archives-ouvertes

\title{
On Gender Specific Perception of Data Sharing in Japan
}

Markus Tschersich, Shinsaku Kiyomoto, Sebastian Pape, Toru Nakamura, Gökhan Bal, Haruo Takasaki, Kai Rannenberg

\section{To cite this version:}

Markus Tschersich, Shinsaku Kiyomoto, Sebastian Pape, Toru Nakamura, Gökhan Bal, et al.. On Gender Specific Perception of Data Sharing in Japan. 31st IFIP International Information Security and Privacy Conference (SEC), May 2016, Ghent, Belgium. pp.150-160, 10.1007/978-3-319-336305_11. hal-01369550

\section{HAL Id: hal-01369550 \\ https://hal.inria.fr/hal-01369550}

Submitted on 21 Sep 2016

HAL is a multi-disciplinary open access archive for the deposit and dissemination of scientific research documents, whether they are published or not. The documents may come from teaching and research institutions in France or abroad, or from public or private research centers.
L'archive ouverte pluridisciplinaire HAL, est destinée au dépôt et à la diffusion de documents scientifiques de niveau recherche, publiés ou non, émanant des établissements d'enseignement et de recherche français ou étrangers, des laboratoires publics ou privés. 


\title{
On Gender Specific Perception of Data Sharing in Japan
}

\author{
Markus Tschersich*, Shinsaku Kiyomoto ${ }^{+}$, Sebastian Pape ${ }^{*}$, Toru Nakamura ${ }^{+}$, \\ Gökhan Bal ${ }^{*}$, Haruo Takasaki ${ }^{+}$, Kai Rannenberg ${ }^{*}$ \\ ${ }^{*}$ Chair of Mobile Business \& Multilateral Security \\ Goethe University Frankfurt, Germany \\ ${ }^{+}$KDDI R\&D Laboratories Inc. \\ Saitama, Japan
}

\begin{abstract}
Privacy and its protection is an important part of the culture in the USA and Europe. Literature in this field lacks empirical data from Japan. Thus, it is difficult - especially for foreign researchers - to understand the situation in Japan. To get a deeper understanding we examined the perception of a topic that is closely related to privacy: the perceived benefits of sharing data and the willingness to share in respect to the benefits for oneself, others and companies. We found a significant impact of the gender to each of the six analysed constructs.
\end{abstract}

\section{Introduction}

In the Western world privacy and its protection is an important part of the culture. In the United States and especially in Europe people care about their privacy and therefore also the majority of research about privacy is based on data collection in NorthAmerica and Europe [1].

Despite some efforts by Asoh et al. [2] and Takasaki et al. [3], literature in the field of privacy lacks empirical data from Japan. Thus, compared to the USA and Europe, it is difficult for foreign researchers to understand the situation in Japan. In Hofstede's taxonomy for cultural patterns $[4,5]$ individualism versus collectivism as a cultural norm is identified as one important criterion. Japanese culture - inspired by Confucian and Buddhism philosophy - differs from western culture where individualism is emphasized [6] and therefore, the protection of oneself has a higher importance. As opposed to this, people of the Japanese culture try to identify their role within the groups they are interacting with [7]. Societal harmony is very important to Japanese people and they try to avoid troubling others [8]. This leads them to be more open to share personal information. Additionally, not sharing data is also often understood as isolation from a group. As data sharing often has a major impact on one's privacy, the perception of sharing is very relevant for the behaviour with regard to privacy and its protection. Besides general cultural differences, also the role of men and women differ between the western and the eastern society. This matches another criterion set by Hofstede $[4,5]$, which distinguishes between cultures that emphasize masculinity

adfa, p. 1, 2011.

(C) Springer-Verlag Berlin Heidelberg 2011 
versus femininity. Based on tenets of Confucianism, taking care on major caregiving responsibilities is the traditional role of women in the Japanese culture [9]. Caused by women's responsibilities in society, the concept of privacy could be more unfamiliar for women than for men. Even though the Japanese society is highly influenced by the western culture, it is interesting to see whether women and men differ in the perceived benefits of sharing data for others and their willingness to e.g. share data.

The paper is structured as follows. Section 2 gives an introduction into privacy research in Japan. Further, Section 2 describes the research model and the hypotheses. In Section 3 the used methodology is explained. Section 4 summarizes the results of the study, followed by a discussion and conclusions in Section 5.

\section{Background and Hypotheses}

\subsection{Related Work}

The economics of privacy including empirical studies relating to the consumer's privacy calculus have been evolving [10]. Especially, from late 1990, with the emerging of the Internet, empirical studies have focused on online shopping or online banking. From 2003, online search and 2005 social networks were in the focus. Chellappa and Sin [11] and other research papers around the same years are mostly based on online shopping or personalized services, which are almost the same category of applications. Consumers' benefits are mostly financial ones (discounts, points, etc.). But for the usage of social networks the consumers' benefits are not financial ones but nonfinancial ones including sharing feelings in a group. A study by Lu et al. [12] demonstrated that social adjustment benefits, i.e. the opportunity of establishing a social identity by integrating into desired social groups, can also have an effect on the intended disclosure behaviour.

The "Act on the Protection of Personal Information" was passed in 2003 and has been enforced in Japan since 2005 [13]. The objectives of this act are to balance the usability of personal information and the protection of individual rights and benefits, and to protect any information that could identify an individual. The act is under revision in terms of expanding coverage of intended data and building an auditing system including privacy commissioners. Recently, for adjusting to the change of international privacy attitudes such as the change in the Privacy Guideline by OECD in 2013 [14], a Consumer Privacy Bill of Rights in US in 2012, and the regulation on the protection of individuals with regards to the processing personal data was passed the European parliament, the law reform proposal on privacy in Japan was published in Jun., 2014. Asoh et al. [2, 15] presented users' privacy concerns in recommendation services using personal data in Japan, and showed that service categories (shopping, navigation and healthcare) did not directly affect to users' privacy concerns. Takasaki et al. [3] analysed privacy concerns for on-line personalization services in Japan. However, in this field there is a lack of empirical data in Japan. This paper intends to show relevant input for designing and implementing privacy protection policies based on empirical data in Japan. 


\subsection{Hypotheses}

Ahead of a potential revelation of personal information humans perform an economic decision-making process [16]. In the so called privacy calculus, users of information systems weigh the potential costs and benefits of sharing their personal information with specific services, institutions, or persons [1, 17-20]. On the risk side, users take into account the privacy concerns as well as the perceived likelihood and damage of a privacy violation.

On the benefit side, users consider positive effects of the revelation of personal information. The benefits highly depend on the type of service a user could reveal personal information to. Literature describes different examples especially from the field of social network sites [21]. However, literature so far focused on personal benefits from the revelation of personal information. A focus on the western world literature might explain all benefits by focusing just on the user itself. For example, Kobsa [22] determined that gender effects on internet privacy concerns could not be clearly established. From our studies, we confirm the gender effects (especially, women with children are more concerned about privacy protection also they tend to show the strong willingness of personalized service usage).

However, in the Japanese culture privacy is a construct that is tied to egotism [23, 24]. Consequently, Japanese users also reflect the benefits for others and also companies. Earlier studies [2, 3, 15] suggest gender effects in Japan. Especially, women with children are more concerned about privacy protection and also tend to show the strong willingness of personalized service usage. Thus, based on the even higher responsibility of Japanese women in society we hypothesize:

- H1a: Female and male Japanese will differ in their perception that they themselves can benefit when they reveal personal information.

- H1b: Female and male Japanese will differ in their perception that others can benefit when they reveal personal information.

- H1c: Female and male Japanese will differ in their perception that companies can benefit when they reveal personal information.

Result of the Privacy Calculus is the intension to reveal personal information [18]. Thus, if users decide to share personal information, they will be willing to reveal for their personal benefit or the benefit of someone else. Also in the willingness to share we expect an impact of the gender due to women's responsibility in the Japanese culture. Therefore, we hypothesize:

- H2a: Female and Male Japanese will differ in their willingness to share personal information for their personal benefit.

- H2b: Female and Male Japanese will differ in their willingness to share personal information for others' benefit.

- H2c: Female and Male Japanese will differ in their willingness to share personal information for companies' benefit. 


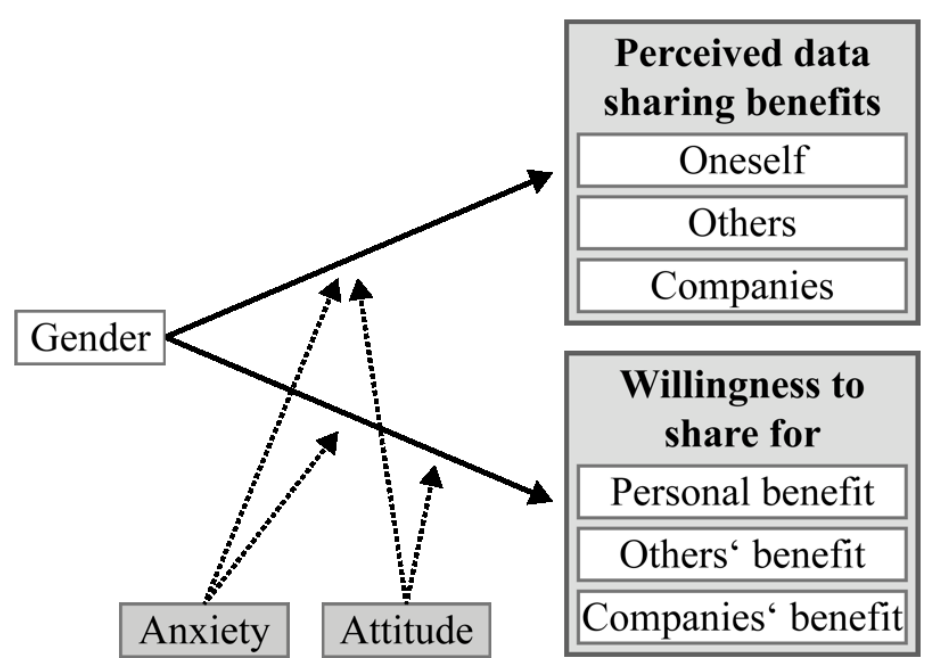

Fig. 1: Overview of the hypotheses and the influencing factors

Users' decisions in the context of computer systems are highly depending on the selfefficacy to specific technologies. Self-efficacy is about what individuals believe about their ability to use a system e.g. effectively [12], and the higher the self-efficacy the greater is the performance achievement. Computer self-efficacy is based on users' attitudes towards computers and their anxiety [25]. Users can differ in their attitude and anxiety and this could bias their decision-making in the privacy calculus and their perceived willingness. Thus, attitude and anxiety are added to our model (cf. Figure 1) as covariates to address this potential bias.

\section{Methodology}

\subsection{Participants}

To get generalizable results, we ran the study with male and female participants with different age and educational background. Overall 9,287 persons participated in the study. For both female and male participants the average age is about 45 years and the distribution to the gender and age groups is also quite equal as shown in Figure 2. 


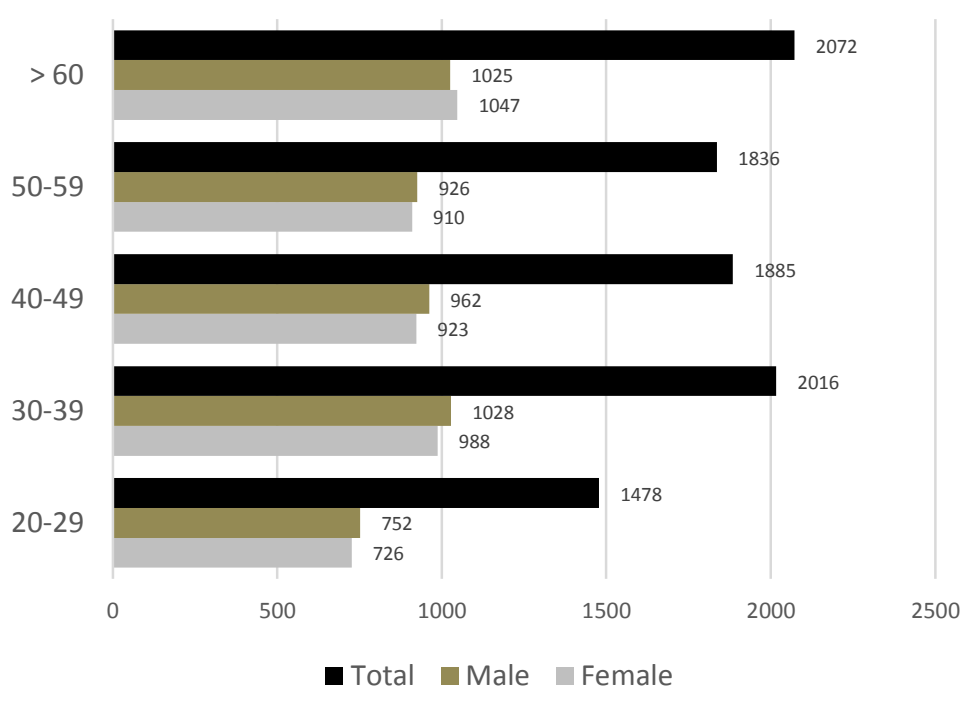

Fig. 2: Gender and age distribution

Participants were collected by publishing an online survey which collected 10000 questionnaires and was executed by a research company. Data was collected from March 12, 2015 until March 19, 2015. We removed responses from people who engaged in research business and advertising business from the participants. We did not select the participants according to where they lived, whether they were married, or whether they had a child, etc.

\subsection{Measurement Instrument}

An instrument was built to measure impact on the perceived benefits or the willingness to share. The measurement instrument is built out of three to five items for each of the six constructs. As literature and theories do not give items for this construct, we created items by ourselves. Table 1 displays the used items per construct.

The use of new and not tested items increases the need of testing their validity and reliability. Therefore, to test the validity a confirmatory factor analysis (CFA) was performed. The results confirm the items of each construct. Subsequently, the reliability of the scale was tested by checking Cronbach's alpha. According to [20] the alpha values as listed in Table 3 are excellent. Further, there was no need to skip items based on the Kaiser-Meyer-Olkin value, because for no construct the dropping of an item increased this value. Thus, we ended up with a measurement instrument including 22 items for the six constructs to be analysed. 
6 On Gender Specific Perception of Data Sharing in Japan

\subsection{Procedure}

The questions were implemented on a web-based questionnaire system by a research company. Selected participants received an instruction for the system from the company, and accessed the system via their own devices. The participants entered their answers via the web-interfaces.

Table 1: Used items per construct

\begin{tabular}{|c|c|c|c|c|c|}
\hline & & \multicolumn{2}{|c|}{ Female } & \multicolumn{2}{|c|}{ Male } \\
\hline & & $\bar{x}$ & SD & $\bar{x}$ & SD \\
\hline \multirow{3}{*}{ 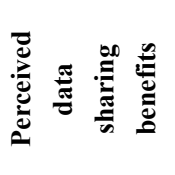 } & Oneself & 3.778 & 1.002 & 3.850 & 1.017 \\
\hline & Others & 3.488 & 1.150 & 3.677 & 1.124 \\
\hline & Companies & 3.855 & 1.102 & 3.999 & 1.062 \\
\hline \multirow{3}{*}{ 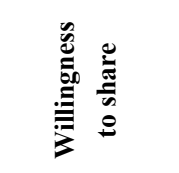 } & Personal benefit & 3.483 & 1.220 & 3.751 & 1.202 \\
\hline & Others' benefit & 3.027 & 1.264 & 3.361 & 1.235 \\
\hline & Companies' benefit & 2.931 & 1.266 & 3.242 & 1.247 \\
\hline
\end{tabular}


7 On Gender Specific Perception of Data Sharing in Japan

Table 2: Constructs on "Perceived privacy benefits"

\begin{tabular}{|c|c|c|}
\hline Construct & Items & $\begin{array}{c}\text { Cronbach's } \\
\text { alpha }\end{array}$ \\
\hline \multirow{5}{*}{$\begin{array}{c}\text { Perceived } \\
\text { data } \\
\text { sharing } \\
\text { benefits } \\
\text { ("Me") }\end{array}$} & $\begin{array}{l}\text { Sharing personal information with online service providers can provide me } \\
\text { with personalized services tailored to my activity context. }\end{array}$ & \multirow{5}{*}{.926} \\
\hline & $\begin{array}{l}\text { Sharing personal information with online service providers can provide me } \\
\text { with more relevant information tailored to my preferences or personal } \\
\text { interests. }\end{array}$ & \\
\hline & $\begin{array}{l}\text { Sharing personal information with online service providers can provide me } \\
\text { with the kind of information or service that I might like. }\end{array}$ & \\
\hline & $\begin{array}{l}\text { In general, I believe that I can profit from sharing personal information with } \\
\text { online service providers. }\end{array}$ & \\
\hline & $\begin{array}{l}\text { I think that I benefit from sharing personal information with online service } \\
\text { providers. }\end{array}$ & \\
\hline \multirow{6}{*}{$\begin{array}{c}\text { Perceived } \\
\text { data } \\
\text { sharing } \\
\text { benefits } \\
\text { ("Others") }\end{array}$} & $\begin{array}{l}\text { It can provide benefits for other people if I share my personal information } \\
\text { with online companies. }\end{array}$ & \multirow{6}{*}{.946} \\
\hline & $\begin{array}{l}\text { If I share my personal information with online companies, other people can } \\
\text { profit from it. }\end{array}$ & \\
\hline & $\begin{array}{l}\text { In general, I think that it is good for other people if I share my personal } \\
\text { information with online companies. }\end{array}$ & \\
\hline & $\begin{array}{l}\text { It can be useful for other people if I share my personal information with } \\
\text { online companies. }\end{array}$ & \\
\hline & $\begin{array}{l}\text { I'm willing to share personal information with online companies if it is } \\
\text { useful for them. }\end{array}$ & \\
\hline & $\begin{array}{l}\text { I'm in general willing to share personal information with online companies, } \\
\text { if I see a benefit for them. }\end{array}$ & \\
\hline \multirow{4}{*}{$\begin{array}{c}\text { Perceived } \\
\text { data } \\
\text { sharing } \\
\text { benefits } \\
\text { ("Compa- } \\
\text { nies") }\end{array}$} & $\begin{array}{l}\text { I believe that online companies can profit from my personal information if I } \\
\text { share it with them. }\end{array}$ & \multirow{4}{*}{.892} \\
\hline & $\begin{array}{l}\text { I believe that it is good for the success of online companies if I share per- } \\
\text { sonal information with them. }\end{array}$ & \\
\hline & $\begin{array}{l}\text { I can support online companies by providing them with my personal infor- } \\
\text { mation. }\end{array}$ & \\
\hline & $\begin{array}{l}\text { I think that it is good for online companies if I provide them with my per- } \\
\text { sonal information. }\end{array}$ & \\
\hline
\end{tabular}


8 On Gender Specific Perception of Data Sharing in Japan

Table 3: Constructs on "Willingness to share"

\begin{tabular}{|c|c|c|}
\hline $\begin{array}{c}\text { Con- } \\
\text { struct }\end{array}$ & Items & $\begin{array}{c}\text { Cronbach's } \\
\text { alpha }\end{array}$ \\
\hline \multirow{3}{*}{$\begin{array}{l}\text { Willing- } \\
\text { ness to } \\
\text { share } \\
\text { (I benefit) }\end{array}$} & $\begin{array}{l}\text { In general, I'm willing to share personal information with online companies } \\
\text { if I can profit from it. }\end{array}$ & \multirow{3}{*}{.916} \\
\hline & $\begin{array}{l}\text { I'm willing to share personal information with online companies if they } \\
\text { provide me with useful services. }\end{array}$ & \\
\hline & $\begin{array}{l}\text { If I see a benefit for myself, I'm in general willing to share personal infor- } \\
\text { mation with online companies. }\end{array}$ & \\
\hline \multirow{3}{*}{$\begin{array}{c}\text { Willing- } \\
\text { ness to } \\
\text { share } \\
\text { (others } \\
\text { benefit) }\end{array}$} & $\begin{array}{l}\text { In general, I'm willing to share personal information with online companies } \\
\text { if other people can profit from it. }\end{array}$ & \multirow{3}{*}{.950} \\
\hline & $\begin{array}{l}\text { I'm willing to share personal information with online companies if they } \\
\text { provide other people with useful services. }\end{array}$ & \\
\hline & $\begin{array}{l}\text { If I see a benefit for other people, I'm in general willing to share personal } \\
\text { information with online companies. }\end{array}$ & \\
\hline \multirow{3}{*}{$\begin{array}{l}\text { Willing- } \\
\text { ness to } \\
\text { share } \\
\text { (compa- } \\
\text { nies } \\
\text { benefit) }\end{array}$} & $\begin{array}{l}\text { In general, I'm willing to share personal information with online companies } \\
\text { if they can profit from it. }\end{array}$ & \multirow{3}{*}{.951} \\
\hline & $\begin{array}{l}\text { I'm willing to share personal information with online companies if it is } \\
\text { useful for them. }\end{array}$ & \\
\hline & $\begin{array}{l}\text { I'm in general willing to share personal information with online companies, } \\
\text { if I see a benefit for them. }\end{array}$ & \\
\hline
\end{tabular}

\section{$4 \quad$ Results}

\subsection{Descriptive Statistics}

We analysed the data set and calculated the mean value and the standard deviation (SD) of the descriptive statistics. Both groups, female and male, were handled individually. This allows a comparison of both groups to identify deviations as displayed in Table 1. The comparison shows that the mean values are lower in the case of the female participants than in the case of the male participants. So compared to the male participants the female participants perceived lower sharing benefits in general. Further they have a lower willingness to share personal information.

Further, in the case of the data sharing benefits, all participants perceive most benefits for companies compared to benefits for themselves or even for others. Participants' highest willingness to share personal is for their own benefit. They are less willing to share for others' benefits and even less for the benefit of companies.

\subsection{Impact Analysis}

To identify the impact of the gender on the different perceived privacy benefits and the willingness to share we run an Analysis of covariance (ANCOVA) for each con- 
struct. The ANCOVA is used, because this statistical method allows handling the influencing factors "Attitudes" and "Anxiety" (that we had identified in Section 2.2) as covariates and so allows filtering out the effect of these influencing factors on the impact. Thus, the bias of attitudes and anxiety of the participants on the result can be prevented, which increases the accuracy of the result. However general linear models like ANCOVA require some assumptions to be fulfilled by the data:

1. The assumption of normality was tested with the Kolmogorov-Smirnov test [26] and reveals that the data of the analysed six constructs is not normal distributed. However, according to the Central Limit Theorem a parametric test can still be used [27].

2. Further, in the case of using ANCOVA the independence of variable (in this case gender) and covariate needs to be checked. The results of the Levene's test [27] indicate that the covariates are independent from each of the analysed six constructs.

The results of the ANCOVA show a highly significant impact of the gender to each of the six analysed constructs. Thus, female and male Japanese people differ in their perception of privacy benefits for oneself, for others and for companies. The same is true for the willingness to share for someone's benefits.

Table 4 shows the result of the ANCOVA. The F-value displays the result of the Ftest as a calculation of the quotient of the variance of the answers of the different experimental groups (in our case women and men). This first step allows the next step, which is the check, whether the null hypothesis $\left(\mathrm{H}_{0}\right)$, that there would be no significant difference between the different experimental groups (men and women), can be falsified. For this we look at the significance levels (Sig., p-values): A p-value below .05 reveals a significant difference between both experimental groups, a pvalue below .001 reveals that the difference is highly significant. Both thresholds are commonly used for this kind of experiments [25]. In our case all the p-values are so small, that they are closer to 0.000 than to 0.001 .

Table 4: Results of the ANCOVA

\begin{tabular}{|c|c|c|c|c|c|c|c|}
\hline & & \multicolumn{2}{|c|}{ Oneself } & \multicolumn{2}{|c|}{ Others } & \multicolumn{2}{|c|}{ Companies } \\
\hline & & $\mathrm{F}$ & $\begin{array}{c}\text { Sig. } \\
\text { (p-value) }\end{array}$ & $\mathrm{F}$ & $\begin{array}{c}\text { Sig. } \\
\text { (p-value) }\end{array}$ & $\mathrm{F}$ & $\begin{array}{c}\text { Sig. } \\
\text { (p-value) }\end{array}$ \\
\hline \multirow{3}{*}{$\begin{array}{c}\text { Perceived } \\
\text { benefit for... }\end{array}$} & Anxiety & 135,503 & .000 & 140,548 & .000 & 56,401 & .000 \\
\hline & Attitudes & 104,633 & .000 & 43,152 & .000 & 79,175 & .000 \\
\hline & Gender & 27,316 & .000 & 105,988 & .000 & 51,217 & .000 \\
\hline \multirow{3}{*}{$\begin{array}{l}\text { Willingness to } \\
\text { share for ... } \\
\text { benefit }\end{array}$} & Anxiety & 114,074 & .000 & 145,547 & .000 & 167,888 & .000 \\
\hline & Attitudes & 90,705 & .000 & 31,918 & .000 & 29,131 & .000 \\
\hline & Gender & 148,010 & .000 & 233,217 & .000 & 213,816 & .000 \\
\hline
\end{tabular}

The high significance (Sig., p-value $<.001$ ) of the covariates "Attitudes" and "Anxiety" as shown in Table 4, demonstrates that the covariates predict the particular dependent variables. Therefore, the perceptions and the willingness are influenced by participants' anxiety and attitudes towards using computer systems. After the effect of 
anxiety and attitudes has been filtered out by the ANCOVA, the adjusted effect of the gender on the six analysed constructs has a significance value of $p<.001$ as displayed in Table 4 as well. Thus, the statistical tests show that the Hypotheses H1a, H1b, and $\mathrm{H} 1 \mathrm{c}$ as well as $\mathrm{H} 2 \mathrm{a}, \mathrm{H} 2 \mathrm{~b}$, and $\mathrm{H} 2 \mathrm{c}$ can be accepted and that the gender of Japanese participants has a significant impact on the perceived benefits and the willingness to share for someone's benefit.

\section{$5 \quad$ Discussion and Conclusion}

The results show a highly significant impact of the gender to each of the six analysed constructs. Thus, female and male Japanese people differ in their perception of privacy benefits for oneself, for others and for companies. The same is true for the willingness to share for someone's benefits. Anxiety and attitudes were identified as biases on the measured effects. However gender still has a significant impact on the effects. Future research should be done to investigate the differences in the perception of privacy in respect to the peoples' culture. It will be interesting if there is a difference between the obtained result for Japan and e.g. Europe or the USA. Additionally, it would be interesting to investigate "Cross-cultural Sharing": Does the willingness to share data with someone belonging to the same culture differ from sharing with someone belonging to another culture?

Further research should also be done regarding the age groups of people. Does the willingness to share data depend on whether they are e.g. Digital Natives or Digital Immigrants [28]?

Finally, practical consequences of our findings should be examined. E.g. would it make sense to offer different services to the different groups?

\section{References}

1. H. J. Smith, T. Dinev, and H. Xu, "Information privacy research: An interdisciplinary review”, MIS Quarterly, vol. 35, no. 4, pp. 989-1015, 2011.

2. H. Asoh, C. Ono, Y. Habu, H. Takasaki, T. Takenaka, and Y. Motomura, “An Acceptance Model of Recommender Systems Based on a Large-Scale Internet Survey", in Advances in user modeling, UMAP 2011 Workshops, Girona, Spain; Lecture Notes in Computer Science, vol. 7138, no. 39, Berlin, Heidelberg: Springer Berlin Heidelberg, 2011, pp. 410-414.

3. H. Takasaki, T. Kouguchi, and T. Jitsuzumi, "A Study on Causes for Privacy Concerns about Personalized Services on Mobile Devices”, Journal of public utility economics, no. 2, pp. 25-34, 2014.

4. G. Hofstede, Culture's Consequences: comparing values, behaviors, institutions, and organizations across nations, 2nd ed. Thousand Oaks, CA: SAGE Publications, 2001.

5. G. Hofstede and G. J. Hofstede, Cultures and Organizations : Software for the Mind, McGraw-Hill Professional, 2004. 
6. M. Nakamura, "Privacy: Current Status and Pending Issues in Japan", NRI Papers, no. 131, 2008.

7. C. L. Miltgen and D. Peyrat-Guillard, "Cultural and generational influences on privacy concerns: a qualitative study in seven European countries", EJIS, vol. 23, no. 2, pp. 103-125, 2014.

8. Y. Orito and K. Murata, "Privacy protection in Japan: cultural influence on the universal value", Electronic proceedings of Ethicomp, 2005.

9. Y. Hashizume, "Gender Issues and Japanese Family- Centered Caregiving for Frail Elderly Parents or Parents- in- Law in Modern Japan: From the Sociocultural and Historical Perspectives", Public Health Nursing, vol. 17, no. 1, pp. 2531, Jan. 2000.

10. C. R. Taylor, "Consumer privacy and the market for customer information", RAND Journal of Economics, pp. 631-650, 2004.

11. R. K. Chellappa and R. G. Sin, "Personalization versus privacy: An empirical examination of the online consumer's dilemma", Information Technology and Management, vol. 6, no. 2, pp. 181-202, 2005.

12. Y. Lu, B. Tan, and K. L. Hui, "Inducing customers to disclose personal information to internet businesses with social adjustment benefits", in Proceedings of 25th International Conference on Information Systems, R. Agarwal, L. J. Kirsch, and J. I. DeGross (eds.), Washington, DC, December 9-12, pp. 272-281, 2004.

13. Japan, Act on the Protection of Personal Information. 2003.

14. OECD, OECD Guidelines on the Protection of Privacy and Transborder Flows of Personal Data.

15. H. Asoh, H. Takasaki, C. Ono, Y. Habu, T. Takenaka, and Y. Motomura, “An Analysis on the Intention to Use Recommendation Services Using Lifelogs", no. 4, pp. 846-854, 2015.

16. N. F. Awad and M. Krishnan, "The personalization privacy paradox: An empirical evaluation of information transparency and the willingness to be profiled online for personalization" MIS Quarterly, vol. 30, no. 1, pp. 13-28, 2006.

17. M. Culnan, "Consumer awareness of name removal procedures: Implications for direct marketing”, Journal of Direct Marketing, 1995.

18. T. Dinev and P. Hart, "An Extended Privacy Calculus Model for E-Commerce Transactions", Information Systems Research, vol. 17, no. 1, pp. 61-80, Mar. 2006.

19. M. Tschersich and R. A. Botha, "Understanding the impact of default privacy settings on self-disclosure in social networking services: Building a conceptual model and measurement instrument", presented at the Proceedings of the 19th Americas Conference on Information Systems, 2013.

20. P. Kline, The Handbook of Psychological Testing, 2nd ed. London: Routledge, 2000.

21. M. Tschersich and R. A. Botha, "Exploring the Impact of Restrictive Default Privacy Settings on the Privacy Calculus on Social Networking Sites", presented at the Twenty Second European Conference on Information Systems, 2014.

22. A. Kobsa, "Privacy-enhanced personalization", Communications of the ACM, 2007. 
12 On Gender Specific Perception of Data Sharing in Japan

23. C. Ess, “'Lost in Translation'?: Intercultural Dialogues on Privacy and Information Ethics (Introduction to Special Issue on Privacy and Data Privacy Protection in Asia)", Ethics Inf Technol, vol. 7, no. 1, pp. 1-6, 2005.

24. K. Kitiyadisai, "Privacy Rights and Protection: Foreign Values in Modern Thai Context", Ethics Inf Technol, vol. 7, no. 1, pp. 17-26, 2005.

25. G. Torzadeh and W. J. Doll, Torzadeh: The Development of a Tool for Measuring... - Google Scholar. Omega, 1999.

26. F. J. Massey Jr, "The Kolmogorov-Smirnov test for goodness of fit", Journal of the American statistical Association, vol. 46, no. 253, pp. 68-78, 1951.

27. A. Field, Discovering statistics using SPSS, 2nd ed. London: Sage Publications Limited, 2006.

28. M. Prensky, Digital Natives, Digital Immigrants. 2001. 